\title{
“ESQUÁLIDAS CRIATURAS DE ASPECTO HORRIPILANTE": A FOME NA LITERATURA SOBRE A SECA DE 1877-79
}

ERIKA GONCALVES DE MENDONCA* SECRETARIA MUNICIPAL DE EDUCACÃO DE MOMBACA

MOMBACA - CEARÁ - BRASIL

MANOEL CARLOS FONSECA DE ALENCAR** UNIVERSIDADE ESTADUAL DO CEARÁ FORTALEZA - CEARÁ - BRASIL

A seca de 1877-79 foi um marco para a produção literária cearense, devido ao momento de crise econômica, política e social, pelo qual estava passando a região que hoje é designada como Nordeste. A partir desse período, a temática da seca passou a ser preponderante em muitos romances, constituindo o que se denomina como "literatura da seca". Esse trabalho busca analisar o modo como três romancistas construíram, RESUMO cada um a seu modo, imagens trágicas sobre a fome que atingia os cearenses. Dentre tais abordagens, destaca-se uma, bem original, que correlaciona a fome como a "doença dos retirantes" e que muito contribuiu para a construção de uma visão estereotipada sobre o povo sertanejo. Essa análise se dá através do estudo comparativo entre as obras Os Retirantes (1879) de José do Patrocínio, A Fome (1890) de Rodolfo Teófilo e Luzia-Homem (1903) de Domingos Olímpio.

Palavras-chave: Fome; Seca; Literatura.

The 1877-79 drought was a milestone for the literary production of Ceará, due to the moment of economic, political, and social crisis, which was going through the region that today is called the Northeast. From that period onwards, the theme of drought became predominant in many novels, constituting what is called "drought literature". This work seeks to analyze the way in which three novelists built each one in its own way, tragic images about the hunger that affected the people of Ceará.

ABSTRACT Among these approaches, there is one, very original, which correlates hunger as the "disease of the retreatants", and which contributed a lot to the construction of a stereotyped vision about the people of the countryside. This analysis takes place through a comparative study between the works Os Retirantes (1879) by José do Patrocínio, A Fome (1890) by Rodolfo Teófilo and Luzia-Homem (1903) by Domingos Olímpio.

Keywords: Hunger; Drought; Literature.

\footnotetext{
* Mestra Interdisciplinar em História e Letras pela Universidade Estadual do Ceará (UECE) e Professora de História da Secretaria Municipal de Educação de Mombaça/CE. E-mail: erikamendonca55@ gmail.com.

${ }^{* *}$ Doutor em História pela Universidade Federal de Minas Gerais (UFMG) e Professor da Universidade Estadual do Ceará (UECE). E-mail: manoel.alencar@uece.br.
} 


\section{INTRODUCÃO}

Diante de uma vasta produção literária e historiográfica sobre a seca de 1877-79, nos interessamos pela forma como a fome é visibilizada em três romances ambientados na província cearense durante aquela estiagem - Os Retirantes (1879) de José do Patrocínio, A Fome (1890) de Rodolfo Teófilo e Luzia-Homem (1903) de Domingos Olímpio. Entre tantos aspectos presentes em cada obra, percebemos que elas possuem em comum o propósito de apresentar imagens realistas e até mesmo trágicas, sobre a fome que atingiu milhares de sertanejos. Porém, tais imagens também se modificam nos escritos de cada autor, conforme as intencionalidades nelas depositadas. Assim, buscamos analisar a leitura que cada autor fazia sobre aquele fenômeno, o modo como a fome se configurou em diferentes estratos sociais, com o propósito de qualificar os sujeitos representados.

Dito que as obras analisadas se aproximam por evidenciar imagens trágicas sobre a seca, nesse sentido, a construção literária que as envolve é pensada aqui como uma "prática social de amplo espectro, isto é, para além do texto publicado, englobando algo que antecede e sucede a essa publicação, como prática de 'trocas intelectuais' entre pares e o engajamento destes nas questões sociais". ${ }^{1}$ Desse modo, é possível relacionar a produção de três obras literárias com o pensamento intelectual brasileiro do último quartel do século XIX. Podemos afirmar que seus autores viam o mundo pela lente do progresso, do ideal de civilização e da modernidade. Sevcenko defende que, em grande parte, os intelectuais desse período tomavam para si a missão modernizadora do país:

Arrojados num processo de transformação social de grandes proporções, do qual eles próprios eram fruto na maior parte das vezes, os intelectuais brasileiros voltaram-se para o fluxo cultural europeu como a verdadeira, única e definitiva tábua de salvação, capaz de selar de uma vez a sorte de um passado obscuro e vazio de possibilidades, e de abrir um mundo novo, liberal, democrático, progressista, abundante de perspectivas ilimitadas como ele prometia. A palavra de ordem da "geração modernista de 1870" era condenar a sociedade "fossilizada"

${ }^{1}$ BARBOSA, I. C. Sertão: um lugar incomum: o sertão do Ceará na literatura do século XIX. Rio de Janeiro: Relume Dumará, 2000, p. 151. 
do Império e pregar as grandes reformas redentoras: "a abolição", "a república", "a democracia". O engajamento se torna a condição ética do homem de letras. ${ }^{2}$

De acordo com Mendes, ${ }^{3}$ José do Patrocínio, Rodolfo Teófilo e Domingos Olímpio eram exemplos de intelectuais representantes dessa "Geração de 1870", pois desenvolviam tanto a atividade intelectual quanto a atividade política nas províncias em que viviam. Além disso, contestavam abertamente o poder imperial ao defenderem as ideias liberais abolicionistas e, em alguns casos, republicanas. Também compartilhavam das discussões teóricas em pauta nos círculos intelectuais, por intermédio dos principais espaços de discussão, tanto através da inserção em agremiações literárias, como por meio da colaboração em periódicos. E ainda, haviam se formado nas instituições brasileiras de ensino superior que funcionavam como principais meios de divulgação das ideias vindas da Europa, sendo a tão agitada década de 1870 o período de formação acadêmica desses três intelectuais. ${ }^{4}$

Fica evidente que detectar pontos em comum entre os autores, auxilia numa melhor compreensão desse tipo de produção. No entanto, a importância conferida a esses aspectos mais amplos deve ser cautelosa, para que os mesmos não ofusquem as diferenças entre os literatos ou aniquilem a originalidade e a riqueza de significados que cada obra proporciona.

\section{UM MESMO CENÁRIO E TRÊS ÂNGULOS DE OBSERVACÃO}

Embora esses autores compartilhassem de concepções mais gerais, cada um foi capaz de fazer uma leitura sobre a seca, a partir das suas próprias experiências individuais e elaborar uma visão particular sobre aquele fenômeno. A começar por José do Patrocínio, esse foi o único que publicou sua obra quando o fenômeno da seca ainda se desenrolava. A obra Os Retirantes resultou do trabalho de observação, para fins jornalísticos, feito por esse autor. O mesmo foi enviado do Rio de Janeiro, pelo jornal carioca Gazeta de Notícias, com a missão de fazer uma

\footnotetext{
${ }^{2}$ SEVCENKO, N. Literatura como missão: tensões sociais e criação cultural na Primeira República. $3^{a}$ ed., São Paulo: Brasiliense, 1983, p. 78-79.

${ }^{3}$ MENDES, A. G. B. A invenção da terra da luz: história, literatura e paisagem (1875-1914). (Dissertação) Mestrado em História, Universidade Federal do Rio Grande do Norte, Natal, 2008, p. 78.

${ }^{4}$ Domingos Olímpio bacharelou-se em Direito, na Faculdade de Direito do Recife em 1873. José do Patrocínio formou-se em Farmácia, na Faculdade de Medicina do Rio de Janeiro, em 1874, embora não tenha exercido tal profissão, dedicando-se ao jornalismo. E Rodolfo Teófilo também se formou em Farmácia, na Faculdade de Medicina da Bahia, em 1876, exercendo, a partir de então, tal profissão, entre tantas outras.
} 
cobertura sobre a seca no Ceará, onde permaneceu entre os meses de maio e setembro, de 1878 . Motta destaca sua atuação numa imprensa combativa, voltada à fiscalização das políticas imperiais:

Patrocínio foi uma voz divergente que manteve um mínimo de sobriedade neste momento, distanciando-se das injunções políticas locais para fazer da agudeza crítica um instrumento perene de trabalho jornalístico. Nesse sentido, talvez nenhum outro jornalista do Império tenha conseguido agenciar maior dose de comoção em torno da seca de 1877 do que ele. Enviado pelo jornal Gazeta de Notícias do Rio de Janeiro para cobrir os efeitos desastrosos da seca e a aplicação das verbas destinadas ao socorro dos retirantes, o jornalista foi uma peça decisiva para a formação de uma pressão pública sobre o Imperador e os governantes da Nação. ${ }^{5}$

A partir dessa citação é importante destacar o fato de Patrocínio ter sido o único, entre os três autores, que não era cearense e, portanto, não estava envolvido com as questões políticas e sociais da província. Mas, nem por isso, a sua fala se torna menos carregada de intencionalidades. Trata-se de alguém responsável por contribuir para construção de uma visão sobre seca. E o seu lugar de fala é bem definido. Distante da tão almejada imparcialidade, Patrocínio vai fundo em suas investigações jornalísticas. E não bastando fazer uma viagem a campo para observar e registrar aquele acontecimento, ele buscou incrementar os seus artigos com a literatura e com a fotografia, para dar uma maior dimensão dos horrores causados por aquela seca.

Assim, ao mesmo tempo em que enviava matérias para o jornal Gazeta de Notícias, também mandava fotografias ${ }^{6}$ dos retirantes famintos para a revista $O$ Besouro e escrevia o romance que seria publicado, primeiramente, em estilo de folhetim, na própria Gazeta de Notícias, ao longo de 1878, sendo concluído e publicado no formato de romance apenas no ano seguinte. Tentando apresentar uma visão completa sobre a seca, ao se utilizar de diferentes

\footnotetext{
${ }^{5}$ MOTTA, F. R. Literatura, fatalidade e história: o jornalismo engajado de José do Patrocínio (1877-1905). (Tese) Doutorado em Comunicação e Semiótica, Pontifícia Universidade Católica de São Paulo, São Paulo, 2008, p. 93.

${ }^{6}$ De acordo com Motta: "No intuito de apresentar uma imagem forte de catástrofe que se abatera sobre os sertanejos em 1878 , Patrocínio fez registrar alguns retirantes, por um obscuro fotógrafo cearense chamado J. Côrrea. Dentre eles, selecionou duas crianças inanidas. Como o jornal Gazeta de Notícias não trabalhava com a veiculação de imagens, Patrocínio enviou as fotografias ao seu amigo, o caricaturista Raphael Bordallo, responsável à época pela revista O Besouro". Ver: MOTTA, 2008, p. 137.
} 
recursos linguísticos, Patrocínio compôs "um potente mecanismo de convencimento da opinião pública que se consorciou com os meios midiáticos da Corte em fins do século XIX, impondose como veículo de denúncia contra o descaso para os afligidos pela Grande Seca de 1877". 7

Fazendo um comparativo entre a escrita de Rodolfo Teófilo e José do Patrocínio, são muitos os pontos que aproximam os romances desses autores, inclusive, no que diz respeito à denúncia dos horrores relacionados à seca, como as várias mortes ocasionadas pela fome, o desvio de socorros públicos, a prostituição, entre outros. É desse modo que Teoberto Landim afirma ser "difícil negar que Rodolfo Teófilo tenha seguido as pegadas de José do Patrocínio". 8 Apesar de seguir um enredo parecido com o de José do Patrocínio, Rodolfo Teófilo apresenta aspectos que são bem singulares de sua escrita e do seu modo de interpretar a realidade.

Mais do que um observador, Rodolfo Teófilo estava envolvido com os problemas da província cearense. Charles Pinheiro afirma que Rodolfo Teófilo, ao perceber o descaso público com que os miseráveis da seca eram tratados, "dedica-se, com espírito altruísta e humanitário, ao socorro das vítimas da varíola e da seca. Ele visitava todos os dias os abarracamentos, levando pessoalmente os medicamentos para a multidão de enfermos". ${ }^{9}$ Diante do seu engajamento social com os problemas da província, "sua escrita era a sua arma de denúncia". ${ }^{10}$ Rodolfo Teófilo fez severas críticas à inabilidade dos responsáveis em gerir recursos para solucionar os problemas relacionados à seca que atingiam a província. Também deixou clara a sua indignação com aqueles da Corte que se opunham aos socorros prestados aos flagelados. Diante de tal engajamento, Rodolfo Teófilo arrogou para si o status de cronista da "Grande seca".

Rodolfo Teófilo era um farmacêutico. Portanto, mais do que uma influência literária, a ciência fazia parte de sua atuação profissional e relacionava-se ao modo como ele percebia os fenômenos a sua volta. Sendo um atuante homem de ciência e de letras, em muitos momentos, Rodolfo Teófilo se apropriou do paradigma médico, difundido pela faculdade baiana, para expressar suas concepções científicas, através de seu romance. De acordo com Flora Süssekind: “Doentes estão no romance de Rodolfo Teófilo dois organismos: o do retirante e a terra seca. E

\footnotetext{
${ }^{7}$ MOTTA, 2008, p. 134.

${ }^{8}$ LANDIM, T. Seca: a estação do inferno. Fortaleza: UFC, 1992, p. 52.

${ }_{9}$ PINHEIRO, C. R. Rodolpho Theophilo: a construção de um romancista. (Dissertação) Mestrado em Letras, Universidade Federal do Ceará, Fortaleza, 2011, p. 42.

${ }^{10}$ PINHEIRO, 2011, p. 42.
} 
tudo se explica no terreno da patologia e dentro dos limites de uma concepção organológica da sociedade brasileira". ${ }^{11}$ A escrita do primeiro romance de Rodolfo Teófilo se caracteriza por um incisivo esforço em se adequar aos parâmetros da literatura naturalista. Para tal propósito, ele recorreu ao uso exacerbado de termos científicos e descrições fisiológicas pormenorizadas para descrever a situação caótica que a fome extremada ocasionava. Exemplo disso são as grotescas cenas de morte por inanição, canibalismo, corpos em decomposição, entre outras.

No que se refere à Luzia-Homem, de Domingos Olímpio, pode-se dizer que, embora esteja no rol das obras classificadas como "literatura da seca" de 1877-79, ela possui aspectos que a diferenciam ainda mais das citadas anteriormente. Aspectos estes, internos e externos do texto, que dizem muito sobre quem a produziu e o seu momento de produção. Primeiramente, destacase o distanciamento entre o tempo cronológico que a obra retrata, referindo-se ao momento de seca vivido na cidade de Sobral em fins de 1878, e o momento em que ela foi publicada, em 1903, ou seja, vinte e cinco anos de diferença. Portanto, o tempo da escrita da obra não é tão próximo do fato narrado, como em A Fome e em Os Retirantes.

Apesar do distanciamento entre esses dois tempos, isso não diminui o papel, reivindicado pelo autor, de testemunha ocular da seca, mas traz implicações relevantes para o modo como a obra foi escrita e revela certas peculiaridades. Assim, é fundamental destacar o lugar social de onde o observador produziu o seu relato. Domingos Olímpio presenciou a seca aos 27 anos, na posição de promotor, desempenhada em sua cidade natal, para onde retornou após concluir o curso de Direito na Faculdade de Recife. Ao contrário do que a acontece em Os Retirantes e em A Fome, o narrador de Luzia-Homem não tem o interesse de denunciar a corrupção das autoridades do poder público em Sobral. A ação do governo, quando é colocada em pauta, é sempre de forma enaltecedora.

Os cidadãos incumbidos pelo Governo da penosa tarefa de distribuir socorros, desempenhavam com excepcional e caridosa dedicação, os seus deveres, mantendo o mais escrupuloso zelo e probidade na administração do serviço. Não houvera ainda um caso de muamba, coisa vulgar em outros centros de afluência de retirantes, nos quais se explorava escandalosamente a miséria, e se desviavam

${ }^{11}$ SÜSSEKIND, F. Tal Brasil, qual romance: uma ideologia estética e sua história: o naturalismo. Rio de Janeiro: Achiamé, 1984, p. 85. 
para serem vendidos por excessivo preço, os víveres destinados aos infelizes famintos. $^{12}$

Enquanto em Os Retirantes e A Fome, como veremos mais detalhadamente, a falta de alimentação é tratada como um problema que atinge de forma devastadora toda a província, em Luzia-Homem, a cidade de Sobral é apresentada como um verdadeiro refúgio para os famintos da seca, onde não falta trabalho, socorros públicos e políticos honestos. Domingos Olímpio, ao descrever a terra natal recorreu a um tratamento evocativo, um estilo mais nostálgico do que naturalista: “A salvação estava em Sobral, na cidade formosa e opulenta, oásis hospitaleiro anelado pelas caravanas de pegureiros esquálidos". ${ }^{13}$

Outro ponto em que a obra de Domingos Olímpio se destaca é no fato de possuir um caráter bem original. Como afirma Teoberto Landim, este "é um romance autenticamente regionalista" ${ }^{14}$ e mesmo classificado por alguns críticos como uma obra naturalista, não se apresenta como uma produção que reivindicava, antes de tudo, esse papel. "Afastando-se em parte do naturalismo do final do século, de influência de E. Zola, Luzia-Homem representa a confirmação de uma corrente estética que já apontava para as causas econômicas e sociais reveladas também a partir da temática da seca". ${ }^{15}$ Para Flora Süssekind ${ }^{16}$, Luzia-Homem aparece como uma fratura do naturalismo. Ao fazer essa ruptura, Olímpio deu prioridade ao saber popular, à religiosidade do povo nordestino e principalmente à ficção, ou seja, não há mais uma busca obsessiva pela verdade científica e pela realidade.

Para Oliveira Junior, Luzia-Homem faz parte de um momento transitório do Realismo e do Naturalismo, se inserindo no que ele denomina como "Pré-Modernismo ou, mais acertadamente, Impressionismo". ${ }^{17}$ Sobre o que se denomina como Impressionismo, Oliveira Junior nos apresenta a definição de Arnold Hauser:

Estilisticamente, o impressionismo é um fenômeno extremamente complexo. $\mathrm{Na}$ realidade, não é mais que o desenvolvimento lógico do naturalismo. Porque se o

\footnotetext{
${ }^{12}$ OLÍMPIO, D. Luzia-Homem. São Paulo: editora Ática, 1996, p. 38.

${ }^{13}$ OLÍMPIO, 1996, p. 131.

${ }^{14}$ LANDIM, 1992, p. 60.

${ }^{15}$ LANDIM, 1992, p. 61.

${ }^{16}$ SÜSSEKIND, 1984, p. 140.

${ }_{17}$ OLIVEIRA JUNIOR, J. L. de. Atualidade de Luzia-Homem. Revista Entrelaces, ano IV, nº 05, maio de 2015.
} 
naturalismo se toma como progresso do geral para o particular, do típico para o individual, da ideia abstrata para a experiência concreta temporal e espacialmente condicionada, então a representação impressionista da realidade, com a ênfase que põe no instantâneo e no único, é uma realização notável do naturalismo. As representações do impressionismo estão mais próximas da experiência sensorial do que as do naturalismo no sentido restrito, e substituem o objeto do conhecimento teórico pelo da experiência ótica mais completamente do que qualquer arte anterior. ${ }^{18}$

A afirmativa de que "as representações do impressionismo estão mais próximas da experiência sensorial" é fundamental para compreendermos a forma como Domingos Olímpio construiu o seu romance. O mesmo, ao retratar a construção de uma cadeia na cidade de Sobral, durante a estiagem de 1877, não fugiu do que se denomina como realidade concreta, pois esses dados são verídicos. Porém, na construção narrativa dessa obra não se percebe uma busca obsessiva, por parte do autor, em se mostrar como um sujeito imparcial, que está ali com o único propósito de retratar a realidade e transformá-la numa linguagem jornalística ou naturalista, como ocorre em Os Retirantes e A Fome. O que prevalece em Luzia- Homem é "a maneira como o autor sentiu a vida em Sobral e a construção da cadeia. Essa vida ficcional parece impregnada do sentimento do artista e de sua vivência no local". ${ }^{19}$

\section{A SECA DE 1877-79 E A LITERATURA REGIONALISTA}

A seca de 1877-79 foi um dos acontecimentos mais marcantes na história da província cearense no século XIX, ocorrendo depois de 32 anos de quadras invernosas e relativa riqueza na província. Durval Albuquerque Júnior destaca que foi a partir dessa estiagem que se construiu a concepção da seca como um problema e a sua vinculação ao "Norte". ${ }^{20}$ Ao

\footnotetext{
${ }^{18}$ HAUSER, 1972. apud OLIVEIRA JUNIOR, 2015, p. 116.

${ }^{19}$ BERGAMIN, M. Luzia-homem só lâmina: uma leitura do romance de Domingos Olímpio (1903). (Dissertação) Mestrado em Ciências da Linguagem, Universidade do Sul de Santa Catarina, Palhoça, 2010, p. 99.

${ }^{20}$ O Norte do país correspondia ao território que atualmente compreende ao Norte e ao Nordeste. O termo Nordeste só veio surgir em 1919 , para designar a parte do Norte sujeita às estiagens e que passou a fazer parte da atuação da Inspetoria Federal de Obras Contra as Secas (IFOCS). Ver: ALBUQUERQUE JÚNIOR, D. M. A invenção do Nordeste e outras artes. 5 ${ }^{\text {a }}$ ed., São Paulo: Cortez, 2011 , p. 81.
} 
apresentar dados comparativos da seca de 1877-79 com outras anteriores, esse autor propôs que tal seca não se diferenciava tanto em termos de intensidade, duração, extensão e nem consequências negativas sociais e econômicas. Não são, portanto, as características do fenômeno climático em si que transformaram essa estiagem em um marco histórico. "Ora, a seca não existe enquanto puro fenômeno, mas como um fato histórico e social e por isso possui imagens e significações que vão variar ao longo do tempo e conforme o contexto social em que se insere". ${ }^{21}$ Nesse sentido, ele propõe que tal fenômeno se revelou como uma síntese de toda a desorganização das relações tradicionais abaladas pelas mudanças em curso. Essas mudanças correspondem ao momento de crise econômica, política e social, pelo qual estava passando a região no final do século XIX.

Em termos econômicos, a seca ocorreu quando uma crise de mercado atingia o principal produto de exportação do Ceará, o algodão. No âmbito político, o deslocamento do polo centralizador econômico do Norte algodoeiro para o Sul cafeeiro foi acompanhado de uma progressiva perda de importância política da classe dominante nortista, mudando também o foco de centralização de poder. ${ }^{22}$

A instabilidade política e econômica pela qual passavam os proprietários rurais resultou em alterações nas relações sociais, devido à quebra do contrato tradicional com os seus dependentes, ficando esses desassistidos diante dos possíveis momentos de calamidade. Neves ${ }^{23}$ destaca que o modelo de organização social tradicional era baseado na relação paternalista de "reciprocidade desigual", na qual o sertanejo oferecia submissão e em troca recebia proteção do proprietário rural. Esse sistema paternalista assegurava, através de frágeis suportes, a estabilidade da vida sertaneja. Essas alterações desembocaram em específicas manifestações de descontentamento e resistências por parte dos dominados às transformações das relações sociais tradicionais. Entre essas manifestações podemos destacar o Quebra Quilos $^{24}$, o banditismo e os movimentos messiânicos. "O Norte é, pois, quando advém a seca

\footnotetext{
${ }^{21}$ ALBUQUERQUE JÚNIOR, D. M. Falas de astúcia e de angústia: a seca no imaginário nordestino - de problema à solução (1877-1922). (Dissertação) Mestrado em História, Universidade Estadual de Campinas, Campinas, 1988, p. 2.

${ }^{22}$ ALBUQUERQUE JÚNIOR, 1988, p. 36.

${ }^{23}$ NEVES, F. de C. A multidão e a história: saques e outras ações de massa no Ceará. Rio de Janeiro: Relume Dumará, 2000, p. $44-47$.

${ }^{24} \mathrm{O}$ Quebra Quilos foi um movimento de revolta das camadas populares contra a cobrança de impostos sobre o consumo e contra a substituição do sistema de pesos e medidas por outro que não conheciam e que beneficiava o comerciante na negociação. Esse movimento destacou-se por seu caráter coletivo. Teve importante atuação em algumas áreas do Norte, mas, não chegou a ter força no Ceará. Porém, é importante para se compreender de forma panorâmica o que estava acontecendo naquela região.
} 
de 1877-79, uma fogueira onde ardem as chamas da mudança que irradia o calor dos conflitos". 25

Esse momento de crise vivido no interior do sertão cearense é bastante significativo para compreendermos o que se diferenciou entre essa seca e as suas antecessoras. Com a desestruturação das relações pessoais estabelecidas no campo, a seca transformou-se "em uma questão de calamidade pública, a ser enfrentada e/ou resolvida no espaço público da cidade, pelo poder público". ${ }^{26} \mathrm{Se}$ antes a fome atemorizava apenas os sertanejos pobres, sendo desconhecida pelos ricos, ao atingir a elite rural, num momento de muitas dificuldades, a seca fez com que alguns de seus membros fossem jogados na miséria. Desse modo, se torna compreensível o fato de que os três romances aqui analisados trazem à tona a trajetória de famílias abastadas que perderam tudo com a estiagem e saíram em retirada em busca de socorros nos principais centros urbanos da província cearense. Esse é o caso das famílias de Manuel de Freitas, em A Fome, de Rogério Monte, em Os Retirantes, e, de Marcos, em LuziaHomem. Ao apresentar a trajetória desse último, Domingos Olímpio deixa explícita a recorrência dessa situação durante aquela estiagem:

Não era raro aparecerem, entre os retirantes, famílias abastadas que haviam abandonado os lares, levando dinheiro e jóias sem valor por não terem o que comprar, mesmo a preços exorbitantes. Marcos, depois de inútil resistência, viuse nessa triste situação. De esperança em esperança de mudança de tempo, vira os gados morrerem nos campos devastados; consumira, com parcimônia cautelosa, as provisões acumuladas, os surrões de farinha de mandioca, os paióis de milho, arroz em casca e feijão; as matalotagens em salmoura ou empilhadas se esgotaram por encanto, porque não tivera coragem de recusar esmola aos famintos que passavam pela sua fazenda. ${ }^{27}$

Em síntese, a consciência da crise passou a ser tomada quando alguns membros da elite rural foram atingidos pela miséria e quando os problemas ocasionados pela seca atingiram a população urbana. Foi a partir dessa situação, tão alarmante nos meios abastados, que os

\footnotetext{
${ }^{25}$ ALBUQUERQUE JÚNIOR, 1988, p. 56.

${ }^{26}$ NEVES. 2000, p. 45-46.

${ }^{27}$ OLÍMPIO, 1996, p. 130.
} 
literatos a tomaram como tema principal para construção de seus romances. Sobre a experiência vivenciada por esses homens letrados em relação a tal fenômeno, Durval Albuquerque destaca que "quase sempre de famílias abastadas, estes autores se sentiam um pouco responsáveis pela situação que vivenciavam e buscavam aliviar suas consciências ao deixar que todo o drama da miséria nortista eclodisse nas páginas de seus livros". ${ }^{28}$

Esse fenômeno, que nunca havia sido vivenciado por muitos intelectuais daquele período, marcou decisivamente a produção escrita, e, mais especificamente, a produção literária sobre o Ceará. Ele serviu de referência para que muitos intelectuais pudessem explicar a realidade local utilizando-se dos referenciais teóricos em vigor. A temática da seca foi um dos fatores preponderantes em quase todos os romances, de forma que o Naturalismo é comumente denominado "literatura da seca". De acordo com Ivone Barbosa:

Do ponto de vista dos estudos literários, cunhou-se um termo para designar a produção literária, de caráter regionalista, que trata do tema da seca no sertão do nordeste - a chamada literatura da seca. Pretendia-se com isso, não apenas classificar tematicamente essa produção, mas também estabelecê-la como um "corpus documental", elegendo-a à condição de testemunho da realidade, até porque, seguindo os cânones naturalistas e os compromissos que os estudos literários impuseram a si, no sentido de resgatar a cultura nacional, esta produção pretendia-se fiel a essa mesma realidade. ${ }^{29}$

É dessa forma que a estiagem de 1877-79 veio marcar o início de um novo tipo de produção literária sobre o Ceará, e, mais especificamente, sobre o universo sertanejo. Até então, a literatura dedicava-se a "resgatar a experiência de conquista e colonização do território cearense pelos portugueses, às lutas contra os índios que aqui habitavam". ${ }^{30}$ Essa literatura que produzia uma imagem bucólica e idílica do sertão deu espaço às imagens trágicas e impactantes da seca. Compreendendo o momento de crise conjuntural vivida por aquela sociedade e o lugar ocupado pelos literatos, entendemos os seus interesses em comover e sensibilizar os leitores para o que se pretendia representar.

\footnotetext{
${ }^{28}$ ALBUQUERQUE JÚNIOR, 1988, p. 223.

${ }^{29}$ BARBOSA, 2000, p. 189.

${ }^{30}$ BARBOSA, 2000, p. 45.
} 


\section{IMAGENS DA SECA E DA FOME}

É do conjunto de obras sobre esse período que se inaugurou uma nova forma de representar o sertão cearense. Assim, novos sentidos lhes foram atribuídos e as concepções de estiagem e fome passaram a ser ressignificadas e reorganizadas. A primeira percepção que obtemos dessas obras sobre aquele momento é de devastação e completo abandono do sertão. É com maestria que José do Patrocínio apresenta esse cenário: "O sertão ressequido estava quase deserto: campos sem gado, povoações abandonadas. E a constante, a implacável ventania, varrendo o céu e a terra, entrava silvando e rugindo, as casas vazias, como fera raivosa, faminta [...]". ${ }^{31}$ Através de uma linguagem metafórica, o autor traçou um paralelo entre a implacável ventania da seca com a sombria atuação devastadora da fome. Igualados pela fome, os sertanejos que saíam em retirada foram apresentados destituídos de suas individualidades e passaram a compor a parte de um todo, de uma multidão.

Eram pedaços da multidão, varrida dos lares pelo flagelo, encalhando no lento percurso da tétrica viagem através do sertão tostado, como terra de maldição ferida pela ira de Deus; esquálidas criaturas de aspecto horripilante, esqueletos automáticos dentro de fantásticos trajes, rendilhados de trapos sórdidos, de uma sujidade nauseante, empapados de sangue purulento das úlceras, que lhes carcomiam a pele, até descobrirem os ossos, nas articulações deformadas. ${ }^{32}$

Essa multidão aparece como uma massa amorfa e disforme, composta por indivíduos sem rosto e sem nome e que se confundem em meio a uma soma de esqueletos que se movem institivamente, repletos de sujidade, úlceras e deformidades. Essas "esquálidas criaturas de aspecto horripilante" compõem o cenário principal dos três romances, o que concorre para uma sensibilização do leitor, podendo provocar diferentes sentimentos, como comoção e até repulsa. Embora em Luzia-Homem, essa percepção seja menos apelativa do que nas outras duas obras, ainda assim, o narrador não deixa de qualificar aqueles sujeitos de tal forma.

\footnotetext{
${ }^{31}$ PATROCÍNIO, J. Os Retirantes. São Paulo: editora Três, 1973, p. 33.

32 OLÍMPIO, 1996, p. 20. Grifo nosso.
} 
O romance de Domingos Olímpio também é o que menos se detém em detalhar cenas trágicas da seca, mas nem por isso deixa de citar as tragédias cotidianas.

\begin{abstract}
Esse espetáculo de todos os dias, na sua monotonia sinistra, não a impressionava mais, porque se habituara à vizinhança da miséria nas formas mais lúgubres e vis. Vira crianças, a sugarem os seios murchos das mães mortas; cadáveres desses entezinhos abandonados sobre a estrada, devorados por urubus e cães vorazes; criaturas ainda vivas e exangues, torturadas pelas bicadas de carcarás a lhes arrancarem, aos pedaços, as carnes ulceradas e podres. Vira mães desnaturadas ocultarem em crateras de formigueiros, o fruto de amores criminosos, ou traficarem com filhas impúberes; pais desalmados, incestuosos e delinquentes dos mais torpes crimes, como se o concurso de todas as dores e de todas as baixezas, condensando-se em enorme e fantástico suplício, os houvera transformado em monstros hediondos, rebalçando-se em lances trágicos de ferocidade inconsciente. $^{33}$
\end{abstract}

Cenas trágicas como essas aqui citadas, são minuciosamente descritas em Os Retirantes e em A Fome. A impressão que nos causam é de completo caos. Esses sujeitos, ao mesmo tempo em que são as principais vítimas da seca, também são transformados em "monstros hediondos", capazes de tudo para garantir a própria sobrevivência. O que se percebe através da literatura da seca é que os sentimentos mais humanos, como o amor pelos filhos, teriam sido aniquilados e as regras básicas de convivência social ficariam suspensas, restando apenas o estado de barbárie. Sobrepondo-se às diferentes imagens que se construíam sobre o sertão, é a fome que aparece, a nosso ver, como a grande protagonista na literatura da seca. A ela foram atribuídos vários sentidos e alguns de forte teor moral, como por exemplo, o encargo de ter sido capaz de submeter os retirantes a uma degradação moral, cometendo os crimes mais torpes.

Em Os Retirantes, o autor destinou um capítulo inteiro para relatar um caso de canibalismo, em que uma mãe mata um filho para servir de alimento a si e ao outro filho. Esse caso é de suma importância, diante da riqueza de detalhes que ele possui e por possibilitar algumas reflexões acerca da perspectiva do autor:

${ }^{33}$ OLÍMPIO, 1996, p. 124. 
O que é verdade é que, para uma mãe fazer o que ela fez, é preciso estar doida. Outros, porém, acudiram logo:

É mesmo por maus bofes; doido não diz coisa com coisa, e ela responde que nem uma letrada.

Diga então qual o crime de que é acusada - ordenou a autoridade dirigindo-se á ré. $[\ldots]$

Matei meu filho! Resmungou a desventurada. [...]

Foi levada por alguma raiva?

Não.

Alguém a obrigou a praticar semelhante ato?

Não; foi minha desgraça.

Mas qual foi esta desgraça?

A fome. ${ }^{34}$

Cenas de canibalismo também são citadas em A Fome, mas é na obra de José do Patrocínio que essa situação é descrita detalhadamente, como uma matéria jornalística de caráter policial. Nesse trecho percebemos o quanto tal prática era abominada por aquela cultura, o que é possível constatar a partir da indignação que o fato ocasionou entre os circunstantes e a tentativa de encontrar uma causa que explicasse o procedimento da acusada. Entre essas causas foram citadas a loucura e até mesmo a maldade de uma desventurada. No entanto, no final do trecho fica bem claro que o grande fator responsável por tal atrocidade foi a fome. Nesse sentido, no contexto de seca e na ausência de recursos alimentares, o que se constata é a presença de práticas canibalescas, recursos totalmente adversos e de confronto à organização daquele sistema cultural. E é essa a imagem que o autor quer mostrar, de uma fome apocalíptica que a tudo devora, penetrando e dissipando os mais íntimos valores humanos, como o cuidado materno, restando apenas o instinto de sobrevivência.

Para além da degradação moral, a fome, antes de tudo, é apresentada na literatura da seca através de uma perspectiva naturalista, como uma condição física que provoca a morte. Essa literatura apresenta a fome como a doença dos retirantes. E isso é enfatizado mais de uma vez em Os Retirantes:

${ }^{34}$ PATROCÍNIO, 1973, p. 117. 
- Lá embaixo está uma epidemia - respondeu o homem - a doença tem atacado muita gente.

- Tem morrido muitas mulheres?

- É onde a doença faz seu roçado, e nas crianças então não falemos.

- Santo Deus! - exclamou Eulália, e foi com as lágrimas a marejarem que perguntou: e como se chama essa doença?

- Ora, é muito de ver! Quem vem de cima não sabe o nome da doença dos retirantes?! É a fome... ${ }^{35}$

O momento que se vivia também possui papel relevante, pois as recentes epidemias chamavam a atenção das análises médicas para as doenças infectocontagiosas e para a necessidade de se estabelecer a higiene pública. Os autores desses romances, em especial José do Patrocínio e Rodolfo Teófilo, elaboraram uma abordagem bem original ao tratar sobre doenças em suas obras. Eles promoveram a fome ao status de doença que merecia atenção e cuidado. Ela foi diferenciada e categorizada entre tantas outras doenças que estavam nas pautas de discussões dos meios científicos e intelectuais, do final do século XIX. Isso porque eles tinham como propósito denunciar a doença que estava matando centenas de sertanejos, pela negligência com que o problema do Norte era tratado pelo poder público.

Em A Fome, Rodolfo Teófilo foi fundo na denúncia sobre o estado de calamidade em que se encontravam aqueles sertanejos e passou a tratar a fome sob a perspectiva fisiológica. Desse modo, a fome, além de um grave problema social, foi pensada, por Rodolfo Teófilo, no âmbito patológico, como um fator capaz de tornar o organismo doente e causar a morte, caso não fosse tratada.

A luz vinha, mas não podia tonificar-lhes os músculos depauperados pela inanição, relaxados pela atonia, pela fome! Nas fisionomias macilentas percebiam-se as torturas impostas pela profunda discrasia do sangue. A miséria e os dias de jejum gastaram as reservas nutritivas acumuladas, comeram os glóbulos vermelhos do sangue, e, uma vez desaparecidos estes da circulação, o líquido nutritivo desfibrado perdera uma das qualidades mecânicas, a densidade, e a vida tornou-se penosa e aflitiva. ${ }^{36}$

\footnotetext{
${ }^{35}$ PATROCÍNIO, 1973, p. 173. Grifo nosso.

${ }^{36}$ TEÓFILO, R. A Fome. Rio de Janeiro: J. Olímpio, 1979, p. 40 e 49. Grifo nosso.
} 
Esses trechos apresentam descrições sobre as reações fisiológicas ocasionadas pelo jejum e pela alimentação pobre em nutrientes nos organismos dos retirantes da seca. Rodolfo Teófilo, através do narrador, procurou demonstrar o seu conhecimento médico sobre o funcionamento do organismo humano. Essa característica se repetiu em vários momentos da obra. Assim, esse autor deixava transparecer em seu primeiro romance, a forte influência da fisiologia ${ }^{37}$ sobre o pensamento médico do período.

Sobre a forma como a fome atuava nos corpos dos sertanejos atingidos pela seca, o geógrafo Josué de Castro ${ }^{38}$ destaca que ela se manifestava de duas formas: tanto qualitativa, como quantitativa. A fome qualitativa mencionada por Josué de Castro está relacionada às carências das substâncias existentes nos alimentos, das quais necessitam para sobreviver e sem elas o corpo passa por um processo de desgaste. Já a fome quantitativa refere-se à perda de massa e gordura, a qual fica visível através das fisionomias desses indivíduos, se traduzindo numa magreza extrema. $\mathrm{O}$ que pudemos constatar a partir da literatura da seca é que são constantes as descrições de corpos famintos e caracterizados por essa magreza aterradora. Isso fica mais evidente através do naturalismo de Rodolfo Teófilo. Vejamos como ele descreve esse corpo faminto:

Não era um bicho mas um homem que a fome reduzira a bicho. Chegando dentro do quiosque pôs-se de pé. Do chão alevantou-se o esqueleto, que media mais de um metro e meio, e tinha a hediondez dos espectros. O tronco largo e bem desenvolvido mostrava ter sido vestido de uma carnação vigorosa, que havia consumido a fome e deixado nuas as vértebras e as costelas. O espinhaço, como uma coluna de nós, apenas coberto de pele, deixava contar todos os ossos. A ele se articulava a cabeça, um pouco mais vestida do que uma caveira, com um rosto esquálido, a fisionomia carregada de ferocidade de animal faminto. Os dentes completos, de branco esmalte, sem lábios mais que cobrissem, num riso perene de ironia e mofa, brilhavam em lúgubres cintilações, mais horripilante tornavamlhe a figura. $\mathrm{O}$ olhar era vago. As pupilas dilatadas quase tocavam-lhe o disco do íris, que lhes servia de debrum, e sepultadas no fundo das órbitas davam á caveira

\footnotetext{
${ }^{37}$ A fisiologia, ciência originada no século XIX, explicava o funcionamento dos órgãos e sua relação com o organismo e compreendia que a vida poderia ser explicada pelo viés físico-químico. Nessa perspectiva, o organismo vivo era visto como uma máquina que dependia do bom funcionamento de seus órgãos para que o indivíduo se mantivesse saudável. Essa compreensão, mais restrita ao paradigma médico, passou a influenciar fortemente o pensamento de Rodolfo Teófilo, desde que esse começou a estudar na Faculdade de Medicina da Bahia. Ver: MENDONÇA, E. G. Literatura, história e ciência no século XIX: a visão naturalista de Rodolfo Teófilo sobre o povo cearense. (Dissertação) Mestrado Interdisciplinar em História e Letras, Universidade Estadual do Ceará, Quixadá, 2020, p. 20-21.

${ }^{38}$ CASTRO, J. de. Geografia da fome. Rio de Janeiro: Gryphus, 1992.
} 
uma expressão de vida, mas de vida de fera. Os braços se estiravam ao longo do tronco envolvidos na pele, que, tendo perdido a frescura e a maciez, enrugada e áspera, parecia de amarrotado pergaminho. As pernas magras, apenas os ossos e um quinto da musculatura, cambaleavam com o peso de carga, pelancas e ossos. O abdômen retraído e colado à espinha deixava perceber as cristas dos ilíacos e a forma da bacia $[\ldots] .{ }^{39}$

É com detalhes minuciosos e exaltados que essa magreza extrema foi descrita. O desejo de transpor a realidade sobre a seca, aspecto esse muito primado por aqueles que se propunham a uma escrita naturalista, fez com que esse literato se utilizasse de descrições muito impactantes para mostrar o que ele considerava como verdadeira face da fome. No entanto, como já dito antes, os famintos da seca não foram anunciados apenas por sua magreza extrema, a eles foram atribuídas características fortemente carregadas de valores e preconceitos. Verifica-se uma incisiva desumanização desses sujeitos, os quais apresentam expressões que remetem a animais ferozes. Expressões tais como: "homem que a fome reduzira a bicho" "vida de fera" e "ferocidade de animal faminto", que os submetem a uma condição de inferioridade.

Embora a fome venha se manifestar nas formas extremas de desnutrição e no padecimento dos corpos famintos, não podemos deixar de atentar para o fato de que essas descrições foram feitas de forma diferenciada de acordo com a posição social e racial dos retirantes, o que revela um olhar de hierarquização e uma forte influência das concepções raciais no romance de Rodolfo Teófilo. É nesse sentido que o narrador, ao relatar sobre a forma como a fome atingiu a Manuel de Freitas, um fazendeiro branco, ele o apresentou como um sujeito diferenciado, capaz de resistir aos infortúnios da seca e demonstrar uma força que o tornava superior às adversidades, pelas quais estava passando.

A fome com o cortejo de dores não pudera apagar os traços daquela carnação. A musculatura estava reduzida, mesmo assim ninguém duvidava que os braços daquele homem pudessem suster um touro pelos cornos. A caixa toráxica bastante larga e bem conformada guardava os órgãos mais importantes da vida são e vigorosos. Naquelas formas não havia um traço que não denotasse virilidade. ${ }^{40}$

\footnotetext{
${ }^{39}$ TEÓFILO, 1979, p. 33.

40 TEÓFILO, 1979, p. 4.
} 
A essa descrição o autor não mais acrescenta características de uma magreza extrema, nem mesmo aspectos de uma fera. Pelo contrário, apresenta a existência de uma força hercúlea que supera as objeções do meio. Nessa obra, a mesma seca que submete os sertanejos pobres e mestiços a uma condição de degradação física e moral, também aparece como um condicionante climático capaz de despertar um tipo ideal forte e resistente a essa natureza. Porém, esses seriam selecionados naturalmente, sobrevivendo apenas os mais aptos, ou seja, a "raça branca" 41, constituída por essas famílias de fazendeiros ricos que haviam se tornado retirantes.

Todas essas descrições contribuíram para a construção de uma representação muito preponderante do sertanejo como um tipo, que exemplifica a expressão síntese do determinismo: "o homem é fruto de seu meio". Essa concepção é tão forte, que a referência mais comum atribuída ao sertanejo é aquela cunhada por Euclides da Cunha, para o qual "o sertanejo é antes de tudo um forte". ${ }^{42}$ Atentamos para o poder de evocação que tal frase revela se pensarmos na definição de sertanejo que ainda persiste. Tal concepção não ficou restrita à literatura da seca, mas se instalou até mesmo em estudos contemporâneos, como é o caso do estudo sobre a fome, realizado por Josué de Castro. Ao falar de como se caracteriza a estrutura física e muscular do sertanejo, esse pesquisador assim o define:

É esta mesma parcimônia calórica, sem margens a luxo, que faz do sertanejo um tipo magro e anguloso, de carnes enxutas, sem arredondamentos de tecidos adiposos [...]. Não o atleta de capa de revista, nem de herói de fita de cinema, atraindo olhares femininos com suas formas apolíneas, mas do atleta fisiológico, com seu sistema neurológico muscular equilibrado, com bastante força e agilidade e com excepcional resistência, nos momentos oportunos. ${ }^{43}$

Fica nítida a referência do sertanejo como um tipo e a sua "excepcional resistência”. É desse modo que atentamos para a importância de se historicizar o uso da palavra sertanejo e sua

\footnotetext{
${ }^{41}$ Em A Fome fica nítida a adoção do darwinismo social para representar e hierarquizar os sertanejos atingidos pela seca. Segundo Maria Augusta Bolsanello, o darwinismo social "considera que os seres humanos são por natureza, desiguais, ou seja, dotados de diversas aptidões inatas, algumas superiores, outras inferiores. A sociedade humana é uma luta "natural' pela vida, portanto é normal que os mais aptos vençam". A teoria das raças (ou determinismo racial), que se desenvolveu no bojo do darwinismo social, considera que essa desigualdade entre os seres humanos se manifesta através de uma hierarquia entre as raças, onde a raça branca se impõe sobre as demais. Ver: BOLSANELLO, M. A. Darwinismo social, eugenia e racismo "científico": sua repercussão na sociedade e na educação brasileira. Educar, Curitiba, n. 12, v. 1, p. 154, 1996.

${ }^{42}$ CUNHA, E. da. Os sertões. São Paulo: Três livros e fascículos, 1984

${ }^{43}$ CASTRO, 1992, p. 207.
} 
imediata referência à seca e à fome. Isso significa abandonar a busca de essências e atemporalidades e admitir que não existe uma definição pronta e acabada para essa categoria, que está sendo construída continuamente. Assim, não existe o sertanejo-tipo, existem diferentes sertanejos. E aqueles representados na literatura da seca tratam-se, em parte, de algo construído sob determinados filtros. Trata-se de uma configuração, entre tantas outras.

\section{CONSIDERACÕES FINAIS}

Vimos que a seca de 1877-79 foi um dos acontecimentos mais marcantes durante o século XIX na província cearense devido ao momento de crise econômica, política e social pelo qual passava a região Norte. Essa seca também serviu de marco histórico na produção literária sobre a região, que ficou conhecida como "literatura da seca". Entre essa produção analisamos três romances que se destacam por enfatizar cenas trágicas ocasionadas pela fome e pela instabilidade social. Esses romances se aproximam por apresentar o drama de famílias sertanejas que perderam tudo e foram jogadas na miséria e também pela tendência naturalista presente na escrita desses três autores, em maior ou menor grau. Porém, cada obra possui características singulares que se revelam de acordo com as vivências e as escolhas literárias de cada autor e as intencionalidades de cada um.

Em A Fome revela-se a perspectiva médica adotada por seu autor ao apresentar um tratamento racial sobre os sertanejos e uma visão patológica sobre a fome que os afligiam. Em Os Retirantes fica mais evidente a manobra literária realizada por um jornalista preocupado em documentar o drama vivido no Norte e construir uma imagem sobre aqueles sertanejos para ser apresentada na corte. Já na obra Luzia-Homem, o seu autor está focado em mostrar a cidade de Sobral como um refúgio, em meio a tanta miséria vivida no restante da província cearense. Apesar das suas especificidades, o conjunto da obra denominada como literatura da seca contribuiu para a construção de uma visão estereotipada sobre o sertão e o povo sertanejo que vem se perpetuando por muito tempo e necessita constantemente ser historicizada e desconstruída. 


\title{
REFERÊNCIAS
}

\author{
Fontes
}

OLÍMPIO, D. Luzia-Homem. São Paulo: editora Ática, 1996.

PATROCÍNIO, J. Os Retirantes. São Paulo: editora Três, 1973.

TEÓFILO, R. A fome. Rio de Janeiro: J. Olímpio, 1979.

\section{Obras Gerais}

ALBUQUERQUE JÚNIOR, D. M. Falas de astúcia e de angústia: a seca no imaginário nordestino - de problema à solução (1877-1922). (Dissertação) Mestrado em História, Universidade Estadual de Campinas, Campinas, 1988.

M. A invenção do Nordeste e outras artes. $5^{\mathrm{a}}$ ed., São Paulo: Cortez, 2011.

BARBOSA, I. C. Sertão: um lugar incomum: o sertão do Ceará na literatura do século XIX. Rio de Janeiro: Relume Dumará, 2000.

BERGAMIN, M. Luzia-homem só lâmina: uma leitura do romance de Domingos Olímpio (1903). Dissertação (Mestrado em Ciências da Linguagem), Universidade do Sul de Santa Catarina, Palhoça, 2010.

BOLSANELLO, M. A. Darwinismo social, eugenia e racismo "científico": sua repercussão na sociedade e na educação brasileira. Educar, Curitiba, v. 1, n. 12, p. 153-165, 1996.

CASTRO, J. de. Geografia da fome. Rio de Janeiro: Gryphus, 1992.

CUNHA, E. da. Os sertões. São Paulo: Três livros e fascículos, 1984.

HAUSER, A. História social da literatura e da arte. 2a ed., São Paulo: Mestre Jou, 1972.

LANDIM, T. Seca: a estação do inferno. Fortaleza: UFC, 1992.

MENDES, A. G. B. A invenção da terra da luz: história, literatura e paisagem (1875-1914). (Dissertação) Mestrado em História, Universidade Federal do Rio Grande do Norte, Natal, 2008.

MENDONÇA, E. G. Literatura, história e ciência no século XIX: a visão naturalista de Rodolfo Teófilo sobre o povo cearense. Dissertação (Mestrado Interdisciplinar em História e Letras), Universidade Estadual do Ceará, Quixadá, 2020. 
MOTTA, F. R. Literatura, fatalidade e história: o jornalismo engajado de José do Patrocínio (1877-1905). Tese (Doutorado em Comunicação e Semiótica), Pontifícia Universidade Católica de São Paulo, São Paulo, 2008.

NEVES, F. de C. A miséria na literatura: José do Patrocínio e a seca de 1878 no Ceará. Revista Tempo, v. 11, n. 22, p. 80-97.

de C. A multidão e a história: saques e outras ações de massa no Ceará. Rio de Janeiro: Relume Dumará, 2000.

OLIVEIRA JUNIOR, J. L. de. Atualidade de Luzia-Homem. Revista Entrelaces, ano IV, $\mathrm{n}^{\circ} 05$, maio de 2015.

PINHEIRO, C. R. Rodolpho Theophilo: a construção de um romancista. Dissertação (Mestrado em Letras), Universidade Federal do Ceará, Fortaleza, 2011.

SEVCENKO, N. Literatura como missão: tensões sociais e criação cultural na Primeira República. $3^{\text {a }}$ ed., São Paulo: Brasiliense, 1983.

SÜSSEKIND, F. Tal Brasil, qual romance: uma ideologia estética e sua história: o naturalismo. Rio de Janeiro: Achiamé, 1984. 